\title{
Поиск и оценка белков нуклеаз II класса в геномных и метагеномных данных
}

Медведев Д.О.*, Желтова А.В.

НИЦ «Курчатовский институт», Москва, Россия

*e-mail:d.o.medvedev@gmail.com

Ключевые слова: CRISPR-Cas, Cas, редактирование генома, ДНК-нуклеазы, Cas12, Cpf1

Мотивация и цель: В прикладном аспекте CRISPR-Cas стал революцией в генной инженерии. Как известно, эффекторы CRISPR-Cas делятся на два больших класса (I и II), на основе структуры эффекторного белка: системы Класса II имеют в качестве эффектора один белок (Cas9, Cas12 (CasX, CasY, Cpf1), Cas13), размером 800-1900 аминокислот [1]. На сегодняшний день репертуар известных эффекторных белков весьма ограничен, а практически используемым эффекторам присущ ряд недостатков. Основной задачей данной работы является анализ инструментов, методов и баз данных для биоинформатического поиска CRISPR-систем в геномных массивах данных с целью расширения спектра известных Cas-эффекторов.

Meтоды и алгоритмы: Был проведен биоинформатический поиск с последующим анализом с целью выявления новых РНК-управляемых ДНК-нуклеаз. Для поиска был применен алгоритм оценки белкового окружения в области обнаруженных белков адаптации обновленных профилей Cas1, Cas2, Csn2 и CRISPR-касет. В ходе работы алгоритма выявляются открытые рамки считывания, каждая из которых проходит аннотации по известным источникам. С помощью алгоритма PSIBLAST были найдены далекие гомологи каждого из белков. Для дальнейшей работы белки были преоретизированы по следующим критериям: процент сходства с известными и используемыми белками, вероятность функциональности домена, размер, оптимум температуры бактерии-хозяина. Результаты: Было отобрано 326 ранее не аннотированных белков, имеющих в своей последовательности нуклеазные домены. Среди отобранных белков была выявлена, наиболее отдаленная от известных последовательностей, находка. Для находки, на основе полученных нуклеотидных сиквенсов, из экспериментальных семплов было предсказано: наличие нуклеазной активности, характеризуйся согласно систематизации, выявление ключевых доменов и аминокислот.

Заключение и доступность: Полученная находка относиться белкам ко второму классу, пятого типа, подтипу А. Анализа множественного выравнивания гомологов белка, а также моделирование структуры по гомологии позволили выявить особенности организации доменов и определить функциональные аминокислоты. Полученные данные, с высокой вероятностью, указывают, что ранее не охарактеризованная находка обладает нуклеазной активностью белков второго класса CRISPR-Cas.

Список литературь

1. Dudek N.K. и др. Novel microbial diversity and functional potential in the marine mammal oral microbiome. Curr. Biol. 2017;27(24):3752-3762.e6. 